Argonne

ANL/CSE-13/19

\title{
Dissolution of Sintered Mo Disks
}

Chemical Science and Engineering Division 


\begin{abstract}
About Argonne National Laboratory
Argonne is a U.S. Department of Energy laboratory managed by UChicago Argonne, LLC under contract DE-AC02-06CH11357. The Laboratory's main facility is outside Chicago, at 9700 South Cass Avenue, Argonne, Illinois 60439. For information about Argonne and its pioneering science and technology programs, see www.anl.gov.
\end{abstract}

\title{
DOCUMENT AVAILABILITY
}

Online Access: U.S. Department of Energy (DOE) reports produced after 1991 and a growing number of pre-1991 documents are available free via DOE's SciTech Connect (http://www.osti.gov/scitech/)

Reports not in digital format may be purchased by the public from the National Technical Information Service (NTIS):

U.S. Department of Commerce

National Technical Information Service

5301 Shawnee Rd

Alexandra, VA 22312

www.ntis.gov

Phone: (800) 553-NTIS (6847) or (703) 605-6000

Fax: (703) 605-6900

Email: orders@ntis.gov

Reports not in digital format are available to DOE and DOE contractors from the Office of Scientific and Technical Information (OSTI):

U.S. Department of Energy

Office of Scientific and Technical Information

P.O. Box 62

Oak Ridge, TN 37831-0062

www.osti.gov

Phone: (865) 576-8401

Fax: (865) 576-5728

Email: reports@osti.gov

\footnotetext{
Disclaimer

This report was prepared as an account of work sponsored by an agency of the United States Government. Neither the United States Government nor any agency thereof, nor UChicago Argonne, LLC, nor any of their employees or officers, makes any warranty, express or implied, or assumes any legal liability or responsibility for the accuracy, completeness, or usefulness of any information, apparatus, product, or process disclosed, or represents that its use would not infringe privately owned rights. Reference herein to any specific commercial product, process, or service by trade name, trademark, manufacturer, or otherwise, does not necessarily constitute or imply its endorsement, recommendation, or favoring by the United States Government or any agency thereof. The views and opinions of document authors expressed herein do not necessarily state or reflect those of the United States Government or any agency thereof, Argonne National Laboratory, or UChicago Argonne, LLC.
} 


\section{Dissolution of Sintered Mo Disks}

by

Peter Tkac ${ }^{1}$, George Vandegrift ${ }^{1}$, and James Harvey ${ }^{2}$

${ }^{1}$ Chemical Science and Engineering Division, Argonne National Laboratory

${ }^{2}$ NorthStar Medical Technologies, LLC

prepared for

U.S. Department of Energy, National Nuclear Security Administration, Office of Defense Nuclear Nonproliferation

July 2012 



\section{CONTENTS}

INTRODUCTION

2 SINTERED Mo DISKS

3 DISSOLUTION OF SINTERED Mo DISKS

4 PACKING DENSITY

5 SINTERING CONDITIONS VERSUS DISSOLUTION KINETICS

6 DISSOLUTION TESTS WITH DISKS MADE OF DIFFERENT MESH

Mo POWDER

7 DISSOLUTION OF HIGHER PACKING DENSITY DISKS

8 DISSOLUTIONS TESTS WITH SEVERAL GRAMS OF Mo AND CONVERSION TO $\mathrm{K}_{2} \mathrm{MoO}_{4}$

9 SUMMARY

\section{FIGURES}

1 Picture of Fresh $12 \mathrm{~mm} \times 1 \mathrm{~mm}$ Sintered Mo Disk and SEM Images

at Three Different Resolutions

2 Photograph and a Series of Scanning Electron Micrographs of Undissolved Residue of Sintered $12 \mathrm{~mm} \times 1 \mathrm{~mm}$ Mo Disk

3 Dependence of Dissolution Rate of Sintered Mo Disks on Different Packing Density

4 Effect of Pre-sinter and Sinter Conditions on the Disk Properties

5 Dissolution Rates for $12 \mathrm{~mm} \times 1 \mathrm{~mm}$ Mo Disks Pre-sintered and Sintered under Different Conditions

6 Dissolution Rates of Disks with Different Sintered History, Made of Powder with Different Particle Sizes 


\section{FIGURES (Cont.)}

7 Comparison of Packing Densities for Disks Pre-sintered and Sintered under Different Conditions, and Made from Powder Sieved through 20- and 400-mesh Sieves

8 Comparison of Dissolution Rates for Disks Pre-sintered and Sintered under Different Conditions, and Made from Powder Sieved through 20- and 400-mesh Sieves

9 Illustration of Mo Disk Position during Dissolution in Hydrogen Peroxide Where a Portion of the Disk is in Contact with Bubbles Formed due to the Decomposition of Hydrogen Peroxide and the Formation of Oxygen, Which Could Accelerate the Dissolution....

10 Comparison of Packing Densities for 71, 81, and 91 Disks Made under Different Pressing Conditions

11 Comparison of Dissolution Rates for 71, 81, and 91 Disks Made under Different Pressing Conditions

\section{TABLES}

1 Comparison of the Dissolution Data for Mo Disks Prepared from

Off-the-Shelf Material and Sintered under Conditions 1 and 2

Distribution of Mo Particle Sizes 


\section{DISSOLUTION OF SINTERED Mo DISKS}

\section{INTRODUCTION}

Processing of irradiated Mo-target disks from the production of Mo-99 using the $(\gamma, \mathrm{n})$ reaction on Mo-100 must be rapid, due to the relatively short half-life of Mo-99 $(\mathrm{T}=66 \mathrm{hr})$. Approximately $1 \%$ of Mo-99 is lost every hour due to its decay. Two potential methods for processing Mo-target disks have been proposed previously as good candidates:

(1) electrochemical dissolution in hydroxide solution (Dale et al. 2010); and (2) dissolution in hydrogen peroxide (Dale et al. 2010; Chemerisov et al. 2011). The main disadvantage of the electrochemical approach was the passivation of the disks during dissolution, which required the addition of hydrogen peroxide. In addition, it was hard to maintain good electrical contact with the Mo disks as the dissolution progressed and the disks shrank. Therefore, more focus was put on processing Mo disks in hydrogen peroxide, because some initial results using sintered Mo disks were very promising (Dale et al. 2010; Chemerisov et al. 2011).

We report experimental results on processing of sintered Mo disks in $30 \%$ hydrogen peroxide. The advantage of this approach is that, after the dissolution of the disks, potassium hydroxide can be added to form potassium molybdate, and excess hydrogen peroxide can be easily destroyed by heating. Dissolution studies of Mo sintered disks were performed in order to better understand how the disks' properties can affect the dissolution rates. From the production point of view, it is desirable to have the highest-density target; putting more Mo-100 in the accelerator beam would lead to a higher Mo-99 yield. However, due to the short half-life of Mo-99, it is also necessary for the processing time for the irradiated target disks to be as short as possible. Experiments were performed to study and optimize the properties of Mo sintered disks for the production of disks with high density and good dissolution rates. 


\section{SINTERED Mo DISKS}

All Mo sintered disks investigated in this work were supplied by NorthStar. They were prepared by pressing Mo metal powder sieved through a 20-mesh sieve (particle size <840 $\mu \mathrm{m}$ ) and then sintered to make a disk with certain dimension. Some disks were made from different particle sizes to investigate its effect on dissolution kinetics; these will be discussed later. The majority of the disks investigated in this work were $12 \mathrm{~mm} \times 1 \mathrm{~mm}$, however, some $26 \mathrm{~mm} \times 1 \mathrm{~mm}$ disks were also studied. A photograph and scanning electron microscope (SEM) images of a $12 \mathrm{~mm} \times 1 \mathrm{~mm}$ Mo disk are shown in Figure 1 .

It should be noted that the disk preparation could have a significant impact on dissolution kinetics; this will be discussed in more detail. The properties of the disk that can significantly affect the dissolution kinetics and that were investigated are (1) packing density, (2) sintering history, and (3) Mo powder particle size. In addition, the dissolution temperature of hydrogen peroxide can play a significant role.

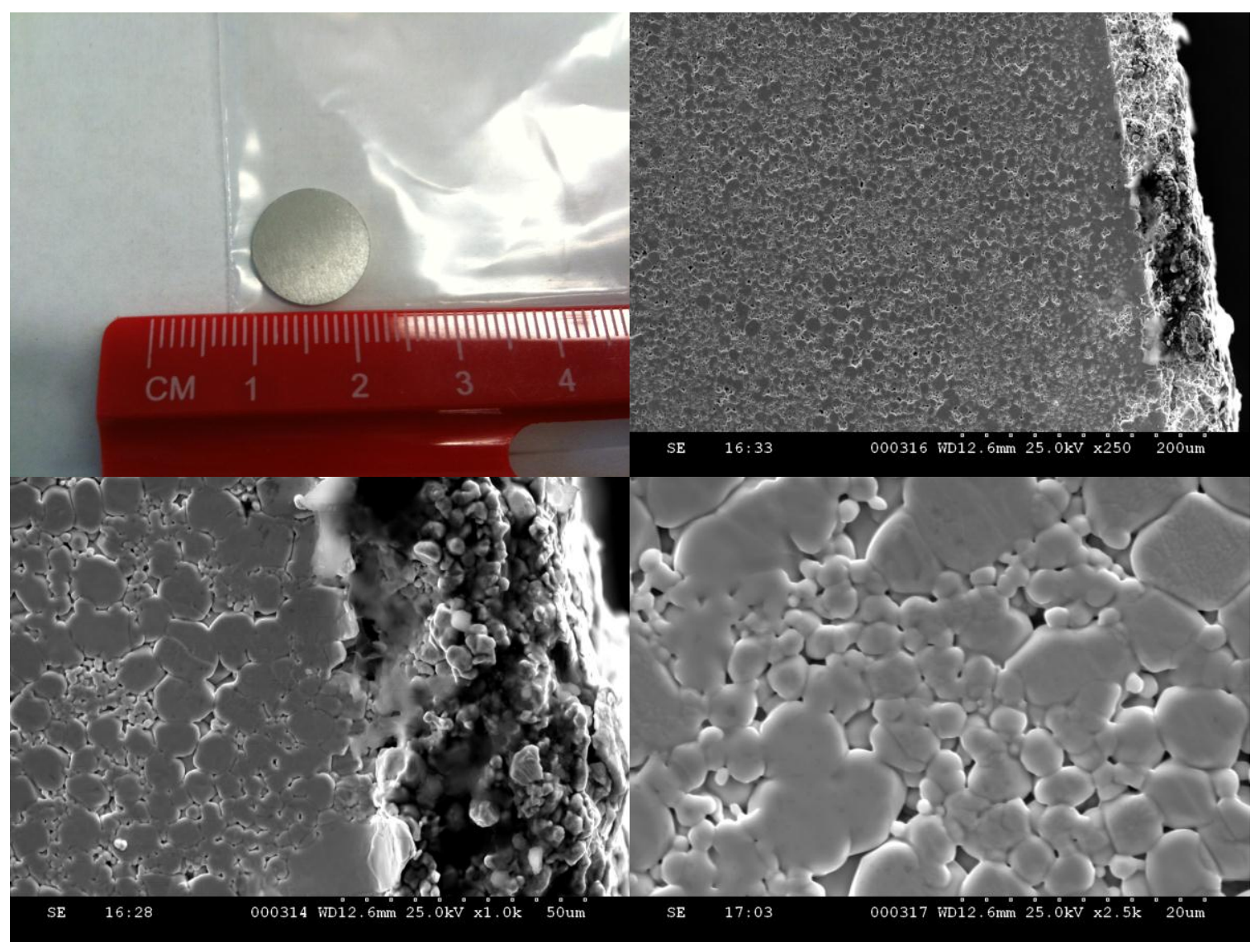

FIGURE 1 Picture of Fresh $12 \mathrm{~mm} \times 1 \mathrm{~mm}$ Sintered Mo Disk and SEM Images at Three Different Resolutions 
A release agent is used during the disk pressing process and helps to keep the disk from cracking, especially when bigger disks are prepared (e.g., $26 \mathrm{~mm} \times 1 \mathrm{~mm}$ disks). In this study, Teflon (PTFE - polytetrafluoroethylene) was used as a release agent for almost all disks. The PTFE is decomposed and volatized under the subsequent sintering conditions.

The sintering history of the disks is described by a two-digit code; each digit refers to the time and temperature applied. The first digit refers to pre-sintering of the metal powder before it is pressed, and the second applies to the final, post-pressing sintering conditions. The numbers range from 0 to 9 ; the lower the number is, the milder the pre-sintering or sintering conditions are (sintered at lower temperature). For example, "91" sintering means that Mo powder was presintered under aggressive conditions, 9 , and then the pressed disk was sintered under very mild conditions, 1 .

The disks initially supplied were prepared from off-the-shelf Mo powder that was purchased from various suppliers and then used for pressing and sintering disks. Off-the-shelf Mo powder was most likely sintered as well; however, since these conditions were unknown, the disks produced from these materials were only described by a sintering condition (e.g., " -2 "). It will be demonstrated that disks made of Mo powder from different suppliers or even from the same supplier but different part numbers can have significantly different dissolution kinetics.

Most of the disks used at the beginning were sintered under condition 9, "-9." The sintering process also affects the dimensions of the disks. More aggressive pre-sinter conditions lead to lower shrinkage of the disks, but potentially also to lower densities. More aggressive sintering conditions lead to greater shrinkage and higher density of the disks. 


\section{DISSOLUTION OF SINTERED Mo DISKS}

Dissolution studies were usually performed in a glass beaker using $40 \mathrm{~mL}$ of $30 \%$ hydrogen peroxide heated to $70^{\circ} \mathrm{C}$. The reaction describing the dissolution of Mo metal in hydrogen peroxide is shown below:

$$
2 \mathrm{Mo}(\mathrm{s})+10 \mathrm{H}_{2} \mathrm{O}_{2}=\left[\mathrm{Mo}_{2} \mathrm{O}_{3}\left(\mathrm{O}_{2}\right)_{4}\left(\mathrm{H}_{2} \mathrm{O}\right)_{2}\right]^{2-}+2 \mathrm{H}_{3} \mathrm{O}^{+}+5 \mathrm{H}_{2} \mathrm{O} .
$$

The reaction is quite vigorous and, due to the auto-destruction of hydrogen peroxide to water and oxygen, produces a lot of bubbles:

$$
2 \mathrm{H}_{2} \mathrm{O}_{2}=2 \mathrm{H}_{2} \mathrm{O}+\mathrm{O}_{2} .
$$

The auto-destruction of hydrogen peroxide is apparently catalyzed by the presence of the Mo disk. When auto-destruction of hydrogen peroxide is very strong, it competes with the oxidation of Mo (eq. [1]), and much more hydrogen peroxide must be added to dissolve the disks.

During the dissolution, the solution turns yellow to orange, depending on the concentrations of Mo and $\mathrm{H}_{2} \mathrm{O}_{2}$. After a complete dissolution of the disks, the solution of Mo in hydrogen peroxide is converted to highly alkaline solution by a careful addition of potassium hydroxide:

$$
2\left[\mathrm{Mo}_{2} \mathrm{O}_{3}\left(\mathrm{O}_{2}\right)_{4}\left(\mathrm{H}_{2} \mathrm{O}\right)_{2}\right]^{2-}+8 \mathrm{KOH}=4 \mathrm{~K}_{2} \mathrm{MoO}_{4} \cdot\left(\mathrm{H}_{2} \mathrm{O}\right)_{2}+5 \mathrm{O}_{2} \text {. }
$$

Addition of $\mathrm{KOH}$ to the Mo solution in hydrogen peroxide also produces a lot of bubbles and heat. The solution is heated to destroy any residual peroxide, and additional $\mathrm{KOH}$ is added to yield a clear and colorless solution of potassium molybdate with $0.2 \mathrm{~g}-\mathrm{Mo} / \mathrm{mL}$ in $5-\mathrm{M} \mathrm{KOH}$. The solution of Mo in 5-M KOH is now ready to be loaded into the TecheGen (NorthStar) generator without any further purification.

In some experiments, the disks would not dissolve even after a prolonged period of time, more than 30 minutes. A photograph and a series of scanning electron micrographs of an undissolved residue of a sintered Mo disk are shown in Figure 2.

Usually, the slowest dissolving disks were the disks with the highest packing densities and strongest sintering conditions, 9. If, after some time, the dissolution did not progress quickly enough, a complete dissolution was usually achieved by adding another portion of fresh $\mathrm{H}_{2} \mathrm{O}_{2}$ and continuous heating at approximately $95-100^{\circ} \mathrm{C}$. Increased temperature decreases the surface tension of hydrogen peroxide and provides better contact with the disk. In addition, at higher temperature and in the presence of Mo metal, hydrogen peroxide decomposes and leads to the formation of oxygen, which can than accelerate the oxidation of $\mathrm{Mo}(0)$ to $\mathrm{Mo}(\mathrm{VI})$. However, if the decomposition of peroxide is too rapid, it can lead to sub-stoichiometric quantities of $\mathrm{H}_{2} \mathrm{O}_{2}$, resulting in prolonged dissolution times and the possible formation of $\mathrm{MoO}_{3}$ or $\mathrm{H}_{2} \mathrm{MoO}_{4}$ precipitates in the absence of peroxide. This will be further discussed. 


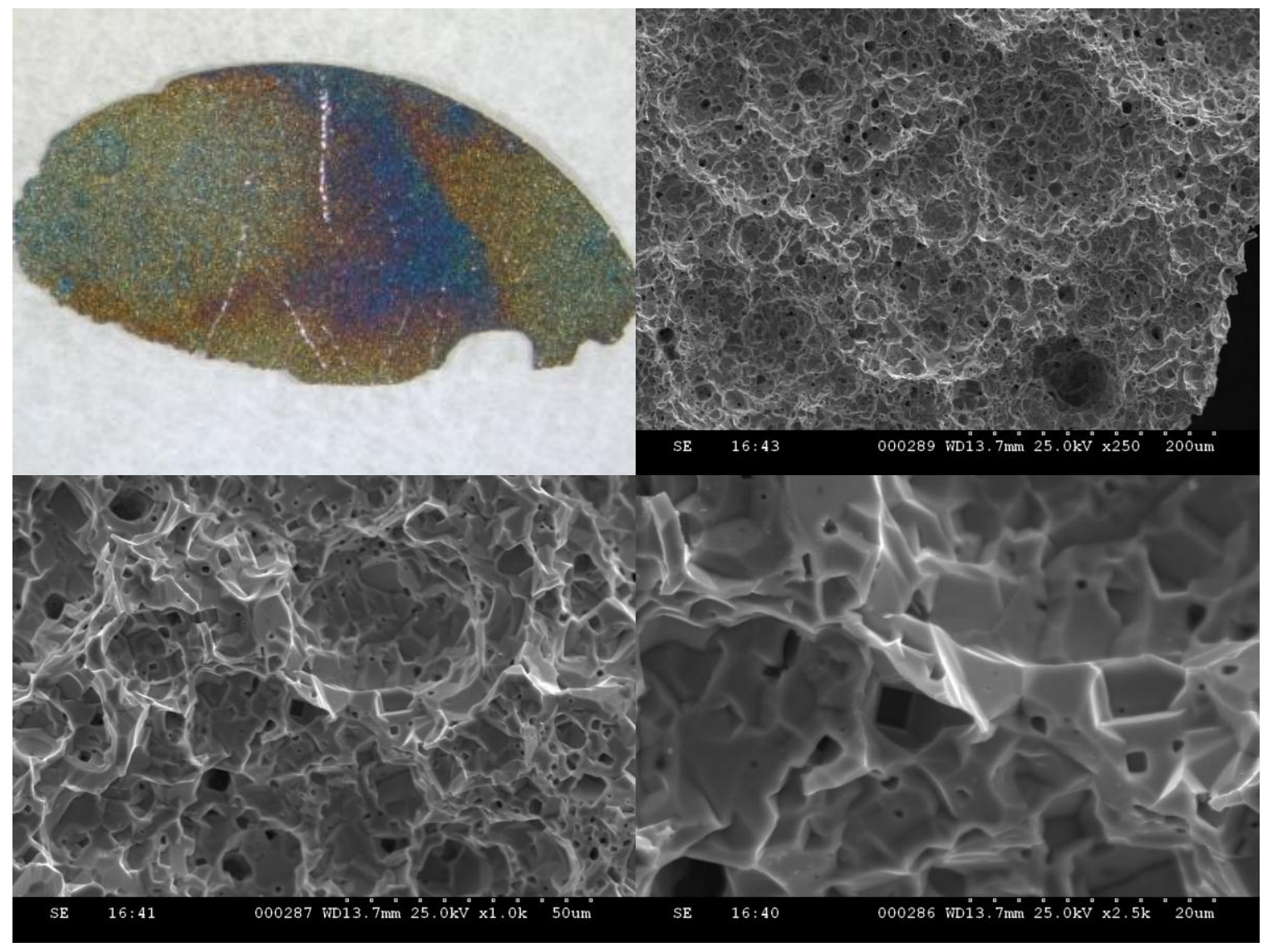

FIGURE 2 Photograph and a Series of Scanning Electron Micrographs of Undissolved Residue of Sintered $12 \mathrm{~mm} \times 1 \mathrm{~mm}$ Mo Disk 


\section{PACKING DENSITY}

Dissolution studies with 10 Mo sintered disks (-9) with packing densities in the range of $56-94 \%$ were performed to study the effect of density on dissolution rates. Except for one disk with an initial density of $56 \%$, the decrease in dissolution rate with packing density is fairly linear up to $88 \%$. For the disks with higher densities, the dissolution rate decreased dramatically (Figure 3).

In order to dissolve the disks with $94 \%$ packing density, a solution of hydrogen peroxide was heated up to $90-95^{\circ} \mathrm{C}$. These $94 \%$ disks dissolved after approximately 13 minutes, while $88 \%$ disks with the same mass dissolved in approximately 2.75 minutes. In addition, some lightly sintered disks (-1) produced with packing densities in the range of $91-92 \%$ had very low dissolution times of approximately 1.5 minutes. The goal for the disk production is to make a disk with packing density of $90-92 \%$ or higher and good dissolution kinetics. Therefore, the next phase of the dissolution study was to determine how the disk production conditions (pre-sinter and sinter) could affect the dissolution of the disks.

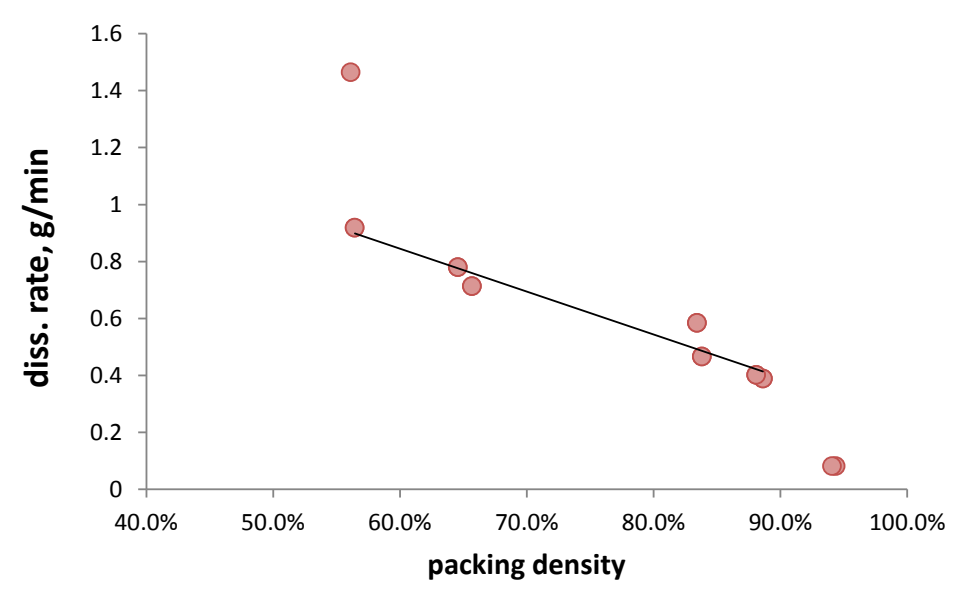

FIGURE 3 Dependence of Dissolution Rate of Sintered Mo Disks on Different Packing Density 


\section{SINTERING CONDITIONS VERSUS DISSOLUTION KINETICS}

Most of the disks in the early stage of this study were made from off-the-shelf powder with -9 sinter. Mo disks with different pre-sintering (-, 9, 7, 0) and sintering $(9,7,2,1)$ conditions were also made for this study. Most of the disks were prepared by the reduction of $\mathrm{MoO}_{3}$ to metal and then pre-sintered and sintered under different conditions, but some disks were prepared from off-the-shelf Mo powder (unknown pre-sinter conditions "-”). The effects of the sintering process on the packing density and dimensions of the disks are shown in Figure 4.

The dissolution studies performed with $12 \mathrm{~mm} \times 1 \mathrm{~mm}(\sim 1.07 \mathrm{~g})$ disks show that the packing density and the sintering process are the most significant factors that affect dissolution rates. Figure 5 shows that the most significant changes in packing densities with different sintering conditions are for the disks prepared from molybdenum powder that was not presintered (" 0 "). The best dissolution rates were observed for the disks in this order: $-1>91>71$ $>92>72>02>-2$. Since the disks made from off-the-shelf material have unknown pre-sinter conditions (if any), it would be hard to directly compare it to the other disks investigated.

The dissolution rates for -1 sintered disks were significantly higher than for other disks investigated (Figure 5). Therefore, to study this in more detail and to see if that could potentially be a future method for disk production, several Mo disks from different lots from two different suppliers were dissolved in $40 \mathrm{~mL}$ of hydrogen peroxide $\left(70^{\circ} \mathrm{C}\right)$.

The dissolution results are shown in Table 1. It is evident that the disks sintered under condition 1 (Table 1) dissolve very quickly despite relatively high packing density $(\geq 91 \%)$.

The dissolution time of -2 disks from the same supplier but different Mo part numbers is in the range of 2.3 to 8.5 minutes. The more than 6-minute difference in dissolution time for similar packing density disks and same sinter conditions is substantial (Table 1).It should be also be pointed out that during the dissolution of the disks from Alfa Part Number 41919, the reaction was so vigorous that all $\mathrm{H}_{2} \mathrm{O}_{2}(40 \mathrm{~mL})$ was completely destroyed after approximately 1 minute and a white precipitate, most likely $\mathrm{H}_{2} \mathrm{MoO}_{4}$, formed. This is most likely due to enhanced catalytic properties of this particular Mo lot, or its pre-sintering (if any) conditions, toward the decomposition of hydrogen peroxide. Complete dissolution was obtained only after adding an additional $20 \mathrm{~mL}$ of $\mathrm{H}_{2} \mathrm{O}_{2}$ and heating. Dissolution of the disks with a very vigorous peroxide auto-destruction reaction is less effective because more hydrogen peroxide is needed for the dissolution. In addition, it is very difficult to control the reaction to avoid the splattering of the solution out of the dissolution container. However, if the reaction is not so vigorous that it would completely destroy all $\mathrm{H}_{2} \mathrm{O}_{2}$ present, some decomposition of peroxide and formation of oxygen could potentially increase the dissolution rates (this will be discussed later in more detail). After processing dissolved Mo-99 in the generator, the residual Mo-100 will be recovered as oxide, reduced back to metal powder, and reused for the production of new enriched Mo-100 sintered disks. Since the variation in properties of off-the-shelf material is relatively high, it is not recommended for future digestion testing unless some commercial material can be identified to react similarly to the as-produced material. 

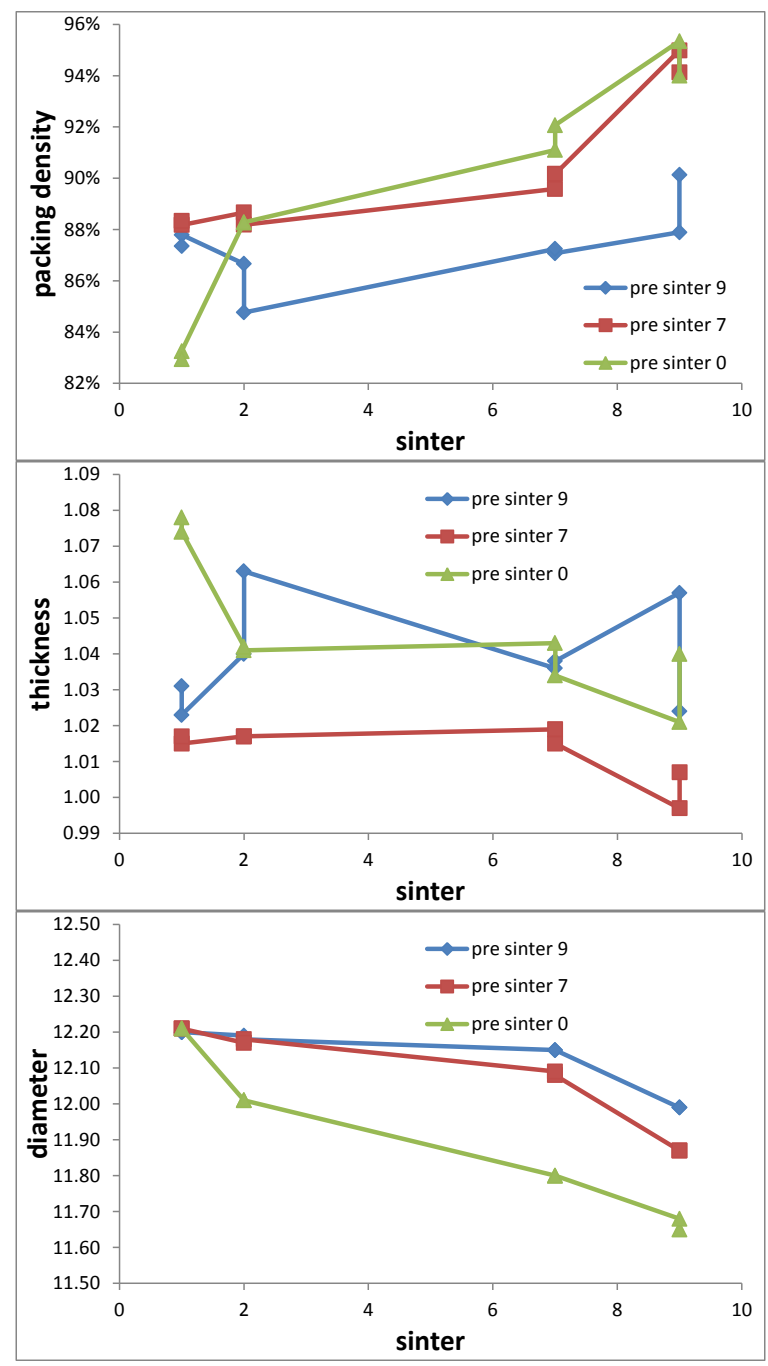

FIGURE 4 Effect of Pre-sinter and Sinter Conditions on the Disk Properties 

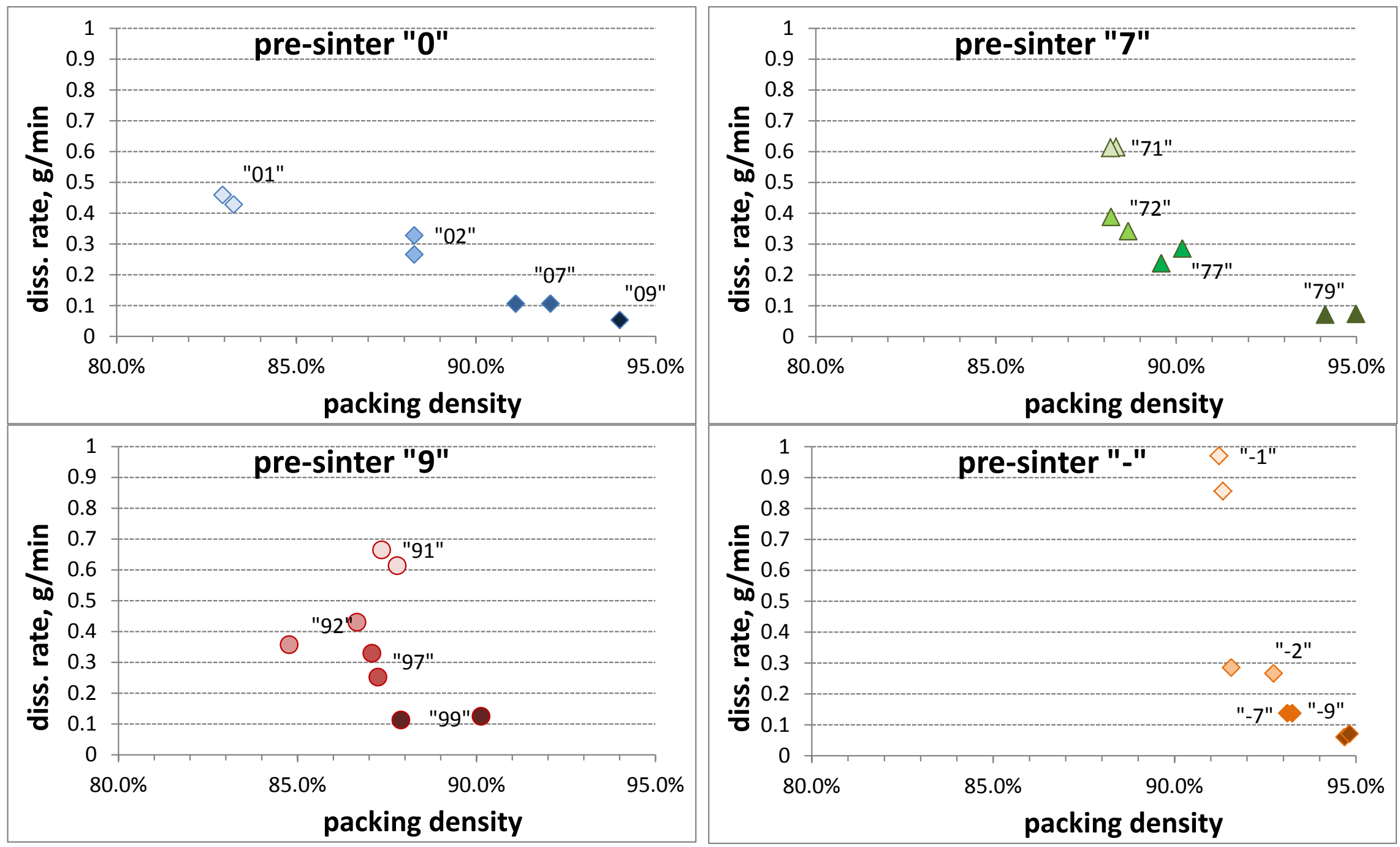

FIGURE 5 Dissolution Rates for $12 \mathrm{~mm} \times 1 \mathrm{~mm}$ Mo Disks Pre-sintered and Sintered under Different Conditions 
TABLE 1 Comparison of the Dissolution Data for Mo Disks Prepared from Off-the-Shelf Material and Sintered under Conditions 1 and 2

\begin{tabular}{|c|c|c|c|c|c|c|c|c|c|c|c|c|}
\hline \multirow[b]{2}{*}{ Parameter } & \multicolumn{12}{|c|}{ Disk Number } \\
\hline & $110806-37$ & $110806-38$ & 110806-39 & $120324-29$ & $120418-08$ & 120418-09 & $120418-10$ & $120418-11$ & $120418-12$ & $120418-13$ & $120418-14$ & $120418-15$ \\
\hline Diameter $(\mathrm{mm})$ & 12.2 & 12.2 & 12.2 & 12.17 & 12.13 & 12.13 & 12.13 & 12.13 & 12.15 & 12.16 & 11.49 & 11.48 \\
\hline Thickness (mm) & 0.98 & 0.974 & 0.972 & 0.983 & 1.009 & 1.002 & 1.011 & 1.018 & 1.032 & 1.031 & 1.23 & 1.188 \\
\hline Mass (g) & 1.072 & 1.073 & 1.069 & 1.07 & 1.069 & 1.068 & 1.059 & 1.05 & 1.069 & 1.068 & 1.063 & 1.064 \\
\hline Density (g/cc) & 9.36 & 9.42 & 9.41 & 9.36 & 9.17 & 9.22 & 9.06 & 8.93 & 8.93 & 8.92 & 8.33 & 8.65 \\
\hline Packing & $91.6 \%$ & $92.2 \%$ & $92.1 \%$ & $91.6 \%$ & $89.7 \%$ & $90.2 \%$ & $88.7 \%$ & $87.3 \%$ & $87.4 \%$ & $87.3 \%$ & $81.6 \%$ & $84.7 \%$ \\
\hline Mo PN & Alfa 00932 & Alfa 00932 & Alfa 00932 & Alfa 00932 & Alfa 10030 & Alfa 10030 & Alfa 10031 & Alfa 10031 & Alfa 41919 & Alfa 41919 & $\begin{array}{l}\text { Aldrich } \\
510092\end{array}$ & $\begin{array}{l}\text { Aldrich } \\
510092\end{array}$ \\
\hline Mo Lot & L26S009C & L26S009C & L26S009C & L26S009C & B26U002 & B26U002 & F15R010 & F15R010B & D24L18 & D24L18 & MKBG6555V & MKBG6555V \\
\hline Sinter Classification & -1 & -1 & -1 & -2 & -2 & -2 & -2 & -2 & -2 & -2 & -2 & -2 \\
\hline Start Temperature & 70 & 70 & 70 & 85 & 70 & 70 & 70 & 70 & 70 & 70 & 70 & 70 \\
\hline $\begin{array}{l}\text { Dissolution Time } \\
\text { (minutes) }\end{array}$ & 1.33 & 1.43 & 1.35 & 3.75 & 5.00 & 5.50 & 2.50 & 3.00 & 8.50 & 8.33 & 2.33 & 2.42 \\
\hline $\mathrm{H}_{2} \mathrm{O}_{2}(\mathrm{~mL})$ & 40 & 40 & 40 & 40 & 40 & 40 & 40 & 40 & $40+20$ & $40+20$ & 40 & 40 \\
\hline Diss. Rate $(\mathrm{g} / \mathrm{min})$ & 0.804 & 0.749 & 0.792 & 0.285 & 0.214 & 0.194 & 0.424 & 0.350 & 0.126 & 0.128 & 0.456 & 0.440 \\
\hline
\end{tabular}




\section{DISSOLUTION TESTS WITH DISKS MADE OF DIFFERENT MESH Mo POWDER}

Several disks with sinter conditions $92,72,52,91,71$, and 51 that were prepared from Mo powder with mesh sizes in the range of 25 to $<500$ and with packing densities in the range of $87.3 \%$ to $88.5 \%$ were studied.

The Mo powder was pre-sintered at three different conditions, 9, 7, and 5, and then ground and sieved into different size ranges (Table 2).

Originally, finer material was expected to have higher impact on increasing the density, but only a small change in density was observed. The dissolution rate, however, increases dramatically with increasing mesh size (decreasing particle size) (Figure 6). The increase in dissolution rate for both 52 and 92 disks made of 100 mesh and 500 mesh was more than a factor of two for the finer-particle disks.

In general, it could be concluded that the disks made of finer material (>200 mesh) dissolve significantly faster than disks made of 20 mesh powder, the current default. When the dissolution rates for the disks made of the same particle size powder but different sintering conditions, 2 and 1, are compared, the disks sintered at 1 dissolved faster by about a factor of two, without any significant changes in the packing density. Therefore, due to very good dissolution kinetics, the disks sintered at 1 would be preferred for disk production over the disks with sinter 2.

TABLE 2 Distribution of Mo Particle Sizes

\begin{tabular}{cr}
\hline $\begin{array}{c}\text { Particle Size } \\
(\mu \mathrm{m})\end{array}$ & Mesh \\
\hline & \\
$710-841$ & 25 \\
$400-710$ & 40 \\
$150-400$ & 100 \\
$105-150$ & 140 \\
$74-105$ & 200 \\
$45-74$ & 300 \\
$37-45$ & 400 \\
$25-37$ & 500 \\
$<25$ & $>500$ \\
\hline
\end{tabular}




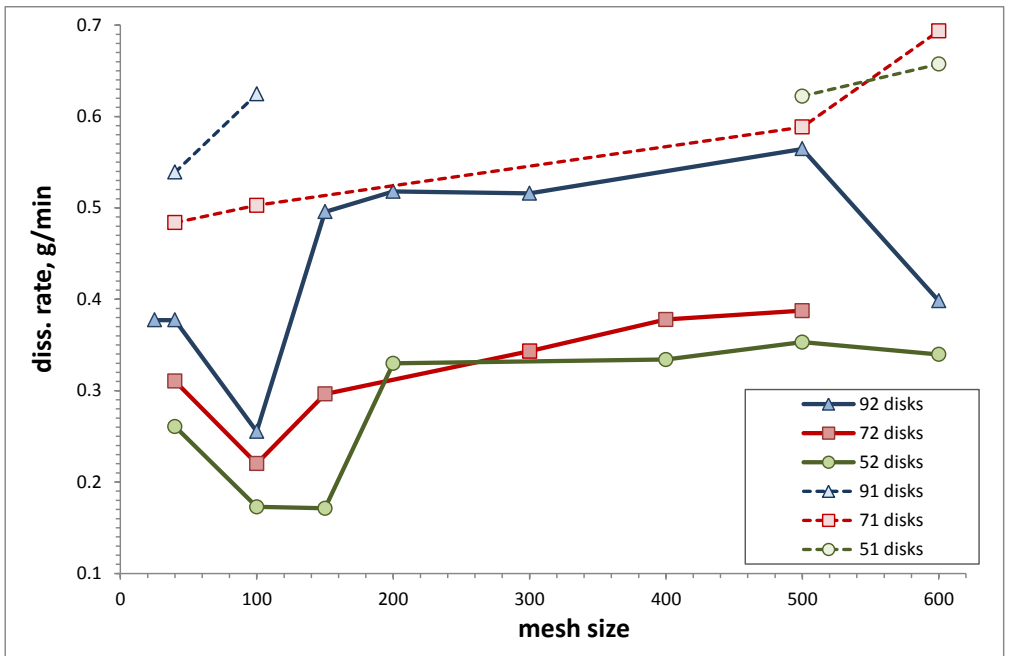

FIGURE 6 Dissolution Rates of Disks with Different Sintered History, Made of Powder with Different Particle Sizes (for reference see Table 2) (The data for disks made of $>500$ mesh are plotted as 600 mesh, although their actual size distribution was not determined.) 


\section{DISSOLUTION OF HIGHER PACKING DENSITY DISKS}

Previous experiments have shown that pre-sinter and sinter conditions can significantly affect the dissolution kinetics. For strong pre-sinter and sinter conditions, the dissolution rates are very low (Figure 4). The data show that especially the disks with strong sintering conditions dissolve very slowly. On the other hand, disks with stronger pre-sinter and milder sinter conditions $(91,71,92$, and 72) show the best dissolution rates. However, the packing densities for these disks were usually in the range of 86-88.5\%. For the production of Mo-99, the disks with higher densities (90-92\% or higher) are preferred to more efficiently utilize the beam and increase throughput. The disks with 77 sinter, on the other hand, have higher packing density, approximately $90 \%$, but the dissolution rates are relatively low. It was shown that disks made of finer particles can dissolve significantly faster than disks made of larger particles (Figure 6). Therefore, we investigated whether the disks made of finer Mo powder (>400 mesh) and sintered under stronger conditions could potentially increase the dissolution kinetics. The disks discussed in this chapter were made of the sintered Mo powder that was ground and simply sieved through 20 and 400 mesh sieves. Therefore, the 20 -mesh disks were made from material with particle sizes $<841 \mu \mathrm{m}$, and 400-mesh disks from material with particle sizes $<37 \mu \mathrm{m}$.

Disks prepared from material pre-sintered at 7,8, and 9 with sinter conditions in the range of 6 to 8 were investigated. The highest packing densities were expected for the disks with milder pre-sinter and strongest sinter conditions (e.g., 78), while the highest dissolution rates were expected for the disks with the strongest pre-sinter and lightest sinter conditions (e.g., 96). Figure 7 compares the packing densities of the disks with pre-sinter 7-9 and sinter 6-9 made from powder sieved through 20-mesh and 400-mesh sieves, respectively. In addition, some disks sintered at 9 are plotted for comparison.

Increase in the packing densities with progressively increased sintering conditions is obvious for all pre-sinter conditions. However, the data indicate that the densities start to decrease if the disks are sintered under condition 9. Unexpectedly, the densities for $>400$-mesh disks are considerably higher than for $>20$-mesh disks and same sintering conditions. This could indicate that stronger sintering conditions are important for increasing the packing density when using finer particles, since the effect with sinter 1 and" 2 and $>400$-mesh powder was not very significant. Comparison of the dissolution rates for the disks pre-sintered at 7, 8, and 9, and sintered at 6,7 , and 8 in $40 \mathrm{~mL}$ of $\mathrm{H}_{2} \mathrm{O}_{2}$ heated to $70^{\circ} \mathrm{C}$ is shown in Figure 8. In addition, some disks sintered at 9 are plotted for comparison.

As expected, the dissolution rates decrease with increased sintering conditions. Very good dissolution rates were observed for the 96 and 97 disks.

Dissolution rates for $>20$-mesh disks with densities in the range of 86-91.4\% decrease with stronger sintering, as expected. The dissolution times were in the range of approximately 2.2-7.25 minutes, with 96 disks dissolving the fastest (average dissolution rate $0.661 \mathrm{~g} / \mathrm{min}$ ). The disks made of $>400$ mesh with densities in the range of 88.6-92.5\% were dissolving significantly faster, and all disks dissolved in 3.75 minutes or less. The fastest dissolving disks were 96 , with an average dissolution rate of $0.76 \mathrm{~g} / \mathrm{min}$. 

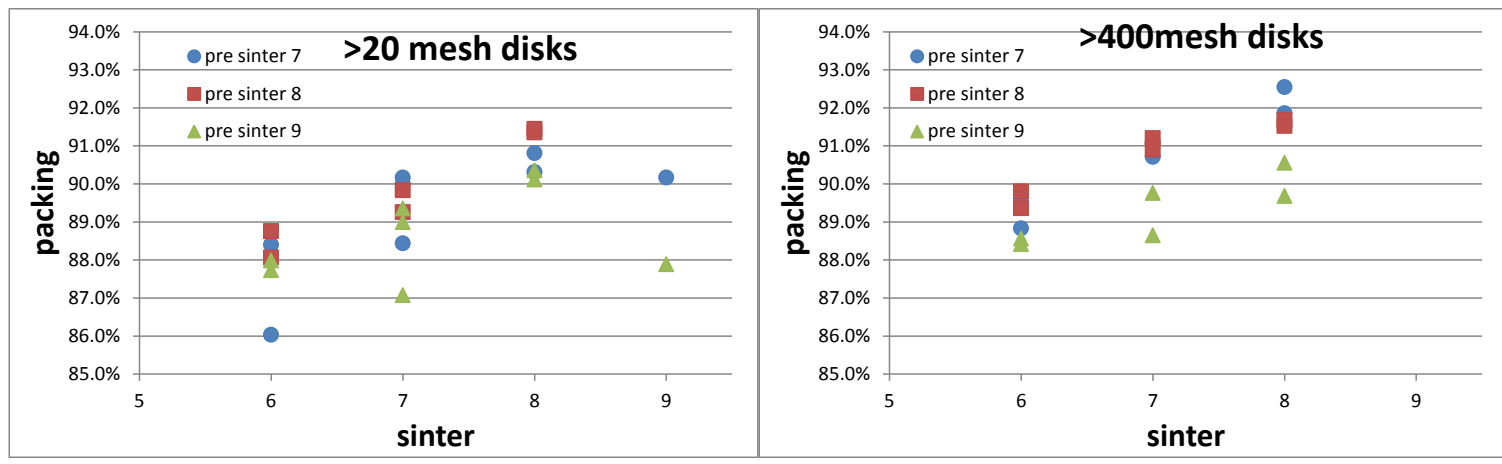

FIGURE 7 Comparison of Packing Densities for Disks Pre-sintered and Sintered under Different Conditions, and Made from Powder Sieved through 20- and 400-mesh Sieves

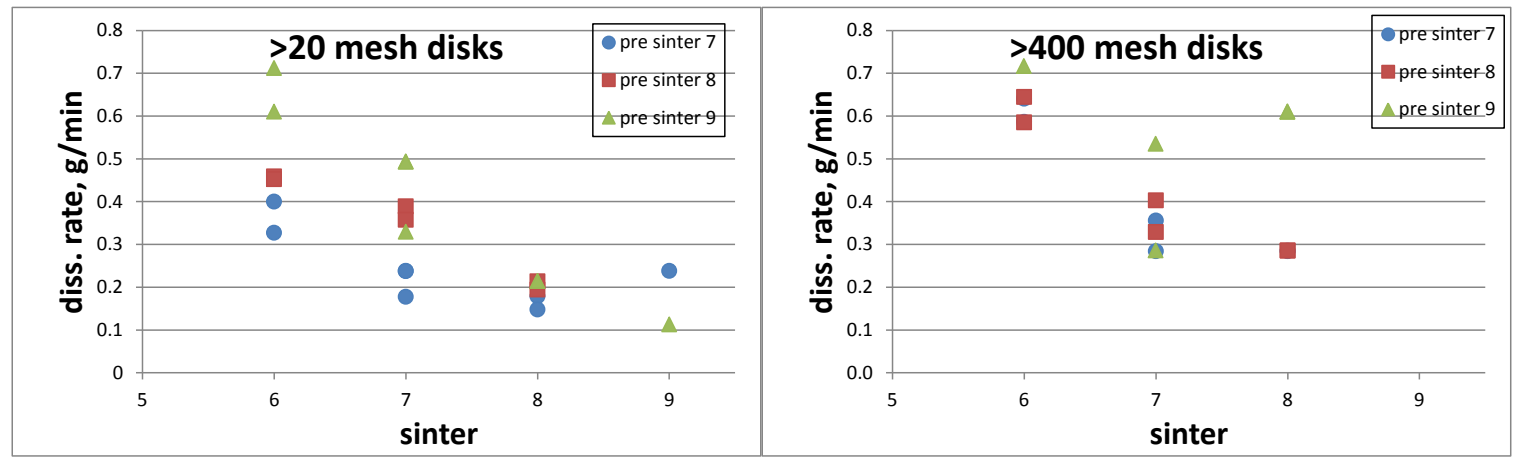

FIGURE 8 Comparison of Dissolution Rates for Disks Pre-sintered and Sintered under Different Conditions, and Made from Powder Sieved through 20- and 400-mesh Sieves

Very interesting behavior was observed for the $98>400$-mesh disks, which dissolved faster than $97>400$-mesh disks. The dissolution rates for 78 and 88 disks were approximately $0.285 \mathrm{~g} / \mathrm{min}$. However, it should be noted that most of these disks dissolved very vigorously with a lot of bubbles forming during the dissolution. This is due to somehow enhanced catalytic properties of these disks toward auto-destruction of $\mathrm{H}_{2} \mathrm{O}_{2}$. A vigorous reaction produces a lot of heat and consumes a significant portion of the hydrogen peroxide; larger containers are necessary to prevent spilling. On the other hand, it was observed that a portion of the disk that was in solution was dissolving slower that the part that was in contact with bubbles (illustrated in Figure 9). This could be due to evolved oxygen from the decomposition of hydrogen peroxide that, in the presence of peroxide, accelerates the oxidation and dissolution of the Mo disks.

Since the fastest dissolving disks are those that were prepared from molybdenum that was pre-sintered under more aggressive conditions, but sintered under very mild conditions, several disks were prepared and dissolved to investigate whether increased packing density would negatively affect these very good dissolution rates. Disks sintered at $1(71,81,91)$ were made under a progressively increased pressing variable to investigate the change in the density and dissolution rates. For these studies, the disks are described by a three-digit code (e.g., "741") where the first digit, 7, is the pre-sinter; second digit, 4 , is the pressing variable;, and the third 


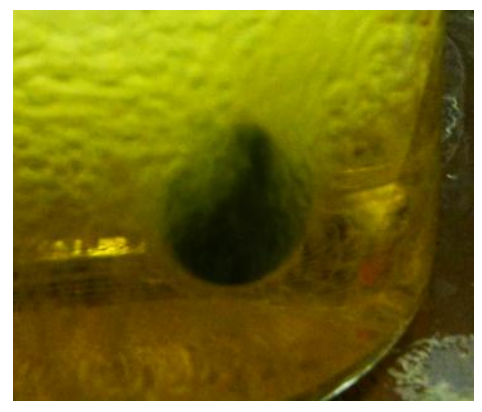

FIGURE 9 Illustration of

Mo Disk Position during

Dissolution in Hydrogen

Peroxide Where a Portion of

the Disk is in Contact with

Bubbles Formed due to the

Decomposition of Hydrogen

Peroxide and the Formation

of Oxygen, Which Could

Accelerate the Dissolution

digit, 1 , is the sintering. Pressing variable 4 is the default for the $12 \mathrm{~mm} \times 1 \mathrm{~mm}$ disks, so a description of the 741 disk is the same as that of the 71 disk.

The densities for the disks sintered at the 71,81 , and 91 conditions with a progressively increased pressing variable from 4 to 8 were in the range of approximately 83-92\% (Figure 10). The increase in packing density as a result of changing the pressing variable from the standard 4 to an aggressive 8 was in the range of approximately $5-7 \%$, which is significant. According to the manufacturer, slightly more aggressive pressing conditions could be applied, which could potentially increase the packing densities even more.

The dissolution rates for 71,81 , and 91 disks with different pressing are shown in Figure 11. All dissolution rates were above $0.55 \mathrm{~g} / \mathrm{min}$, which is very good. All disks dissolved in the range of 1.5 to 2 minutes. For the same packing density, the dissolution time decreases from 71 to 81 to 91 , with 91 dissolving the fastest, but changes were not very significant. The dissolution studies indicate that an increase in density from $83 \%$ to $92 \%$ had almost no effect on the dissolution time, with a difference of only 10-20 seconds. 


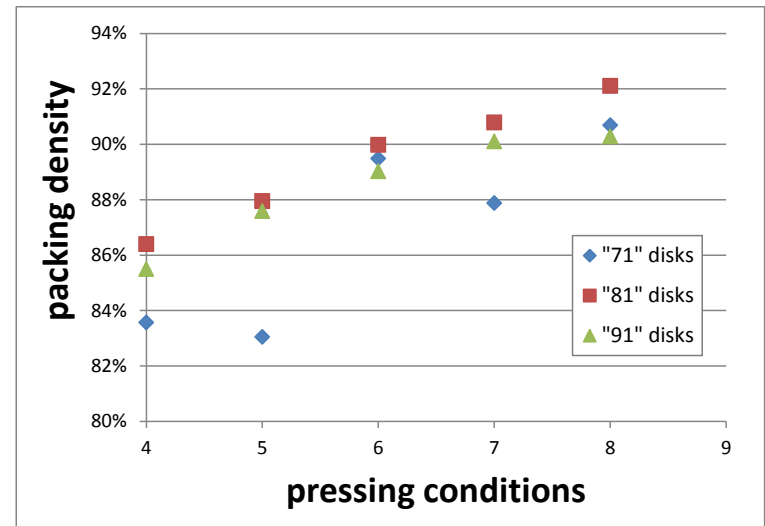

FIGURE 10 Comparison of Packing

Densities for 71, 81, and 91 Disks Made under Different Pressing Conditions

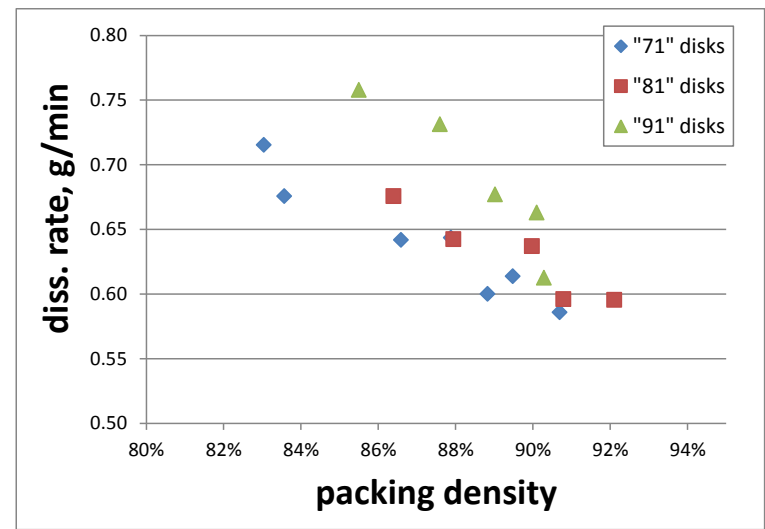

FIGURE 11 Comparison of Dissolution Rates for 71, 81, and 91 Disks Made under Different Pressing Conditions 


\section{DISSOLUTIONS TESTS WITH SEVERAL GRAMS OF Mo AND CONVERSION TO $\mathrm{K}_{2} \mathrm{MoO}_{4}$}

Dissolution of two sets of six $26 \mathrm{~mm} \times 1 \mathrm{~mm}$ Mo sintered disks in hydrogen peroxide was performed to estimate the processing time for the dissolution of a whole target consisting of twenty-five $12 \mathrm{~mm} \times 1 \mathrm{~mm}$ disks. The total mass of $28.3 \mathrm{~g}$ and $25.4 \mathrm{~g}$ with an average packing density of $83.4 \%$ and $88.4 \%$, respectively, were dissolved. For the first batch (83.4\% packing density), after approximately 17 minutes, an estimated $>99.5 \%$ of disks were dissolved using $300 \mathrm{~mL}$ of $\mathrm{H}_{2} \mathrm{O}_{2}$, and only a few very small pieces remained undissolved. A complete dissolution was achieved with additional heating after approximately 30 minutes. A second batch of the disks $(88.4 \%)$ was dissolved using continuous addition of fresh hydrogen peroxide $(400 \mathrm{~mL})$ and removing the solution of $\mathrm{H}_{2} \mathrm{O}_{2}$ containing dissolved Mo. The disks fully dissolved in less than 20 minutes. Hydrogen peroxide containing dissolved Mo was then heated and $\mathrm{KOH}$ was added to destroy peroxide and form a solution of potassium molybdate. In both cases, the total processing time for the dissolution and conversion of $\mathrm{Mo}$ into $\mathrm{K}_{2} \mathrm{MoO}_{4}$ in 5-M KOH with a concentration of $0.2 \mathrm{~g}-\mathrm{Mo} / \mathrm{mL}$ was approximately 45 minutes, which is very good. However, for the second batch, the addition of $\mathrm{KOH}$ led to the formation of some brownish-orange precipitate that has also been observed in the past in some experiments and could be due to the presence of some impurities in the disks or a formation of some stable Mo-peroxo species. 


\section{SUMMARY}

Dissolution studies have been focused on several factors that could potentially affect processing of Mo disks. It was demonstrated that stronger pre-sinter and sinter conditions lead to the lowest dissolution rates. Milder pre-sinter, or no pre-sinter, and very strong sinter conditions usually lead to the disks with highest packing densities and lowest dissolution rates. In contrast, stronger pre-sinter conditions and very mild sinter conditions lead to higher dissolution rates.

Moreover, the experiments performed confirm that size of the Mo powder used for a disk production can affect both the density and the dissolution rate. In general, the disks made of finer particles (>400 mesh) can dissolve significantly faster than the disks made of $>20$-mesh powder. The disks that dissolve the fastest are the 91,81 , and 71 disks, and it was demonstrated that packing density for these disks can be increased by increasing the pressing variable without any significant effect on the dissolution kinetics.

Disks fabricated under the 96 and 97 conditions dissolved very fast and should be further investigated because of their potential for further increase in packing density from stronger pressing.

The dissolution studies with up to $28.3 \mathrm{~g}$ of Mo showed that processing time necessary for the dissolution and conversion of the solution into $\mathrm{K}_{2} \mathrm{MoO}_{4}$ in $5-\mathrm{M} \mathrm{KOH}$ with a concentration of $0.2 \mathrm{~g}-\mathrm{Mo} / \mathrm{mL}$ is less than an hour, which is very good.

Future experiments should focus on optimizing pressing conditions to increase packing density without compromising dissolution rates, and the use of $>400$-mesh powder. The experiments should focus on 91, 81, 71, 96, and 97 disks.

In addition, the orange precipitate that sometimes forms after conversion of Mo-peroxo species into potassium molybdate should be investigated in more detail. 


\section{REFERENCES}

Chemerisov, S., V. Makarashvili, B. Micklich, C. Jonah, J. Bailey, P. Tkac, and G. Vandegrift, 2011, Accelerator Technology for Mo-99 Production by the $\gamma, n$ Reaction on Mo-100, FY-2011 Progress Report, Los Alamos National Laboratory.

Dale, G., S. Chemerisov, G. Vandegrift, P. Tkac, K. Woloshun, H. Bach, C. Heath, C. Kelsey, D. Bowers, A. Guelis, C. Jonah, R. McCrady, E. Olivas, K. Hurtle, E. Pitcher, F. Romero, W. Tuzel, J. Gioia, T. Tomei, R. Wheat Jr., M. DeCroix, D. Warren, D. Dalmas, B. Romero, and J. Harvey, 2010, Global Threat Reduction Initiative (GTRI) Accelerator Production of ${ }^{99} \mathrm{Mo}$, FY10 Report, Los Alamos National Laboratory, September 30. 



\section{Argonne}

Chemical Science and Engineering Division

Argonne National Laboratory

9700 South Cass Avenue, Bldg. 205

Argonne, IL 60439-4837

www.anl.gov 